\title{
Tetrandrine enhances cytotoxicity of cisplatin in human drug-resistant esophageal squamous carcinoma cells by inhibition of multidrug resistance-associated protein 1
}

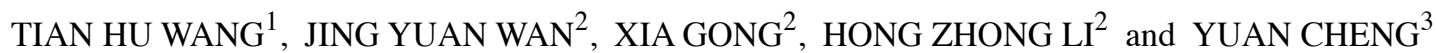 \\ ${ }^{1}$ Department of Cardiothoracic Surgery, The Second Affiliated Hospital, Chongqing Medical University, \\ Chongqing 400010; ${ }^{2}$ Chongqing Key Laboratory of Biochemistry and Molecular Pharmacology, \\ Chongqing Medical University, Chongqing 400016; ${ }^{3}$ Department of Neurosurgery, The Second \\ Affiliated Hospital, Chongqing Medical University, Chongqing 400010, P.R. China
}

Received May 11, 2012; Accepted July 23, 2012

DOI: 10.3892/or.2012.1999

\begin{abstract}
Multidrug resistance is one of the major causes limiting the efficacy of chemotherapeutic agents to control esophageal cancer. Herein, we investigated that the effect and mechanism of tetrandrine (TET) in the human esophageal squamous carcinoma cisplatin-resistant cell line YES-2/DDP. The human esophageal squamous carcinoma cisplatin-resistant cell line YES-2/DDP was isolated by stepwise selection in increasing concentrations of cisplatin. The CCK-8 method was carried out to measure the cell viability when cells were exposed to TET with or without cisplatin, and the $\mathrm{IC}_{50}$ and resistance index (RI) of cisplatin was then calculated. Real-time RT-PCR and western blotting were used to detect the mRNA and protein expression of multidrug resistance 1 (MDR1), multidrug resistance-associated protein 1 (MRP1) and breast cancer resistance protein (BCRP), respectively. Flow cytometry was adopted to determine CMFDA efflux and cell apoptosis, respectively. The resulting cell line YES-2/ DDP was 16.4-fold resistant to cisplatin, the cytotoxicity of cisplatin to YES-2/DDP cells was enhanced by TET in a dosedependent manner. Further, it was found that the expression of MDR1 and BCRP was similar in different treated cells. In contrast, the expression of MRP1 was markedly increased in YES-2/DDP cells, which was dose-dependently decreased by TET. In agreement with the results, MRP1 activity was also reversed by TET. In conclusion, TET possesses a reversal effect on drug resistance in YES-2/DDP cells through downregulation of MRP1, and has the potential to be an adjunct to chemotherapy for esophageal cancer.
\end{abstract}

Correspondence to: Professor Yuan Cheng, Department of Neurosurgery, The Second Affiliated Hospital, Chongqing Medical University, 1 Yixueyuan Road, Chongqing 400016, P.R. China

E-mail: chengyuan023@yahoo.com.cn

Key words: tetrandrine, multidrug-resistant, oesophageal squamous carcinoma, multidrug resistance-associated protein 1

\section{Introduction}

Chemotherapy is regarded as an important line of defense against esophageal cancer which is one of the most aggressive and lethal malignancies. However, on account of drug resistance especially multi-drug resistance (MDR), only a limited proportion of cancer patients respond favorably to commonly used chemotherapeutic drugs (1). With respect to the mechanisms of drug resistance, ATP-binding cassette (ABC) transporters, such as $\mathrm{ABCB} 1 /$ multidrug resistance 1 (MDR1), ABCC1/multidrug resistance-associated protein 1 (MRP1) and ABCG2/breast cancer resistance protein (BCRP), mediate energy-dependent drug efflux and play a main role in chemoresistance $(2,3)$. Therefore, it seems imperative to find new drugs or methods especially targeting ABC transporters to reverse tumor drug-resistance.

Tetrandrine (TET) (Fig. 1), a bis-benzylisoquinoline alkaloid isolated from the Chinese herb 'Han-Fang-Ji' (Radix Stephania tetrandra S. Moore), has been found to have immunosuppressive, free radical scavenging and anti-inflammatory activities (4-6). Furthermore, many recent studies have shown that TET exerts antitumor effects $(7,8)$. In addition to inhibiting proliferation and inducing apoptosis of several cancer types, TET has exhibited potential as an adjunct to chemotherapy in many drug-resistant cancer cell lines $(9,10)$. However, it remains unclear whether TET can reverse ABC transporter-mediated drug efflux. Moreover, it is also unknown whether TET can be used as an adjunct to chemotherapy for esophageal cancer.

In this study, a human esophageal squamous carcinoma cell line (YES-2) was selected by stepwise exposure to increasing concentrations of cisplatin to produce a cisplatin-resistance esophageal cancer cell line (YES-2/DDP). We examined whether TET can effectively reverse cisplatin resistance in YES-2/DDP and evaluated its possible mechanisms.

\section{Materials and methods}

Materials. TET $\left(\mathrm{C}_{38} \mathrm{H}_{42} \mathrm{O}_{6} \mathrm{~N}_{2}, \mathrm{MW}: 622.8\right.$, purity $\left.\geq 98 \%\right)$ determined by HPLC as previously described (11) was the product of Sigma Chemical Company (St. Louis, MO, USA). Cisplatin 
was obtained from Qilu Pharmaceutical Company (Shandong, China). MDR1, MRP1 and BCRP were purchased from Chemicon International (Temecula, CA, USA), and $\beta$-actin antibodies were products of Cell Signaling Technology (Boston, MA, USA). Bicinchoninic acid (BCA) protein assay kit and enhancer chemiluminescent (ECL) reagents were obtained from Pierce Biotechnology (Rockford, IL). Cell Counting Kit-8 (CCK-8) and Annexin V-FITC Apoptosis detection kit were purchased from Beyotime Institute of Biotechnology (Nanjing, China) and KeyGen Biotech (Nanjing, China) respectively. Chloromethylfluorescein diacetate (CMFDA) were obtained from Invitrogen (Carlsbad, CA, USA).

Cell lines and cell culture. YES-2 cells, a human esophageal squamous carcinoma cell line, and its cisplatin-resistant cell subline, YES-2/DDP, were cultured in DMEM medium with $10 \%$ fetal bovine serum, penicillin $(100 \mathrm{U} / \mathrm{ml})$ and streptomycin $(100 \mathrm{U} / \mathrm{ml})$, and maintained at $37^{\circ} \mathrm{C}$ in a humidified atmosphere of $5 \% \mathrm{CO}_{2}$. The cisplatin-resistant cells of YES-2/DDP were isolated by stepwise selection in increasing concentrations of cisplatin starting with $0.01 \mu \mathrm{g} / \mathrm{ml}$. When cells became confluent in medium containing cisplatin, the drug concentration was increased to $0.03,0.05,0.1,0.3,0.5$, and $1 \mu \mathrm{g} / \mathrm{ml}$, the maximal concentration used. The YES-2/DDP cell subline was passaged in cisplatin-free medium and remained stably resistant to cisplatin for several months. To prevent the outgrowth of revertants, the cells were periodically reselected in the presence of $0.1 \mu \mathrm{g} / \mathrm{ml}$ cisplatin. Under these conditions no change in resistance was observed over 1.5 years.

Cell viability. The effects of TET and/or cisplatin on the growth of YES-2/DDP and YES-2 cells were measured by CCK-8 method. The cells were dispensed in 96-well plate at a density of $1 \times 10^{5}$ cells per well. After $24 \mathrm{~h}$ of incubation, they were treated with different concentration of TET and/or cisplatin, and were cultured for $72 \mathrm{~h}$. After such treatments, the cells were incubated with $20 \mu \mathrm{l} \mathrm{CCK}-8$ for $2 \mathrm{~h}$ at $37^{\circ} \mathrm{C}$, and then measured the absorbance at $450 \mathrm{~nm}$ using model 550 microplate reader (Bio-Rad, USA). The cell growth inhibition was determined by triplicate assays. The half of inhibition concentrations $\left(\mathrm{IC}_{50}\right)$ values were calculated from cytotoxicity curves. The resistance index (RI) was calculated by dividing the $\mathrm{IC}_{50}$ for MDR cells by that for parental sensitive cells.

Apoptosis of cells. To measure the apoptosis of cells, annexin V-FITC Apoptosis detection kit was used. Annexin V binding on the surface of apoptotic cells expressing phosphatidylserine and propidium iodide (PI) incorporation by dead cells were analyzed by using standard protocols. Briefly, cells were detached by trypsin treatment, resuspended in PBS at a concentration of $10^{5}$ cells $/ \mathrm{ml}$, and labeled with $5 \mu \mathrm{l}$ Annexin V-FITC for $10 \mathrm{~min}$. After addition of $10 \mu \mathrm{l} \mathrm{PI}$, the samples were analyzed by flow cytometry.

Quantitative reverse transcription-PCR. Total RNA was isolated from cells using TRIzol reagent according to the manufacturer's protocol. First-strand complementary DNA (cDNA) was synthesized. The reverse transcription was conducted by incubating for $60 \mathrm{~min}$ at $43^{\circ} \mathrm{C}$ followed by $10 \mathrm{~min}$ at $70^{\circ} \mathrm{C}$. SYBR $^{\circledR}$ Premix Ex Taq ${ }^{\mathrm{TM}}$ (Takara) was used to quantitatively

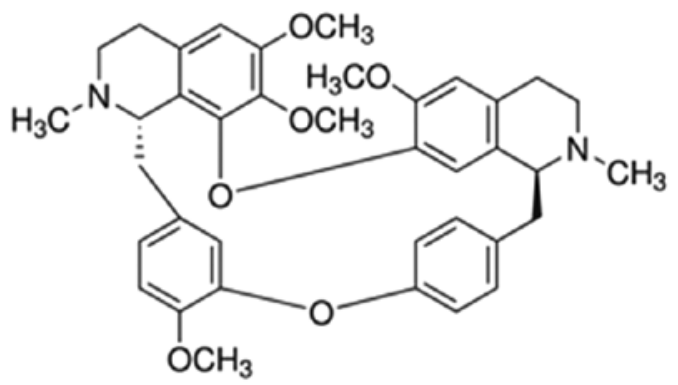

Figure 1. Chemical structure of TET.

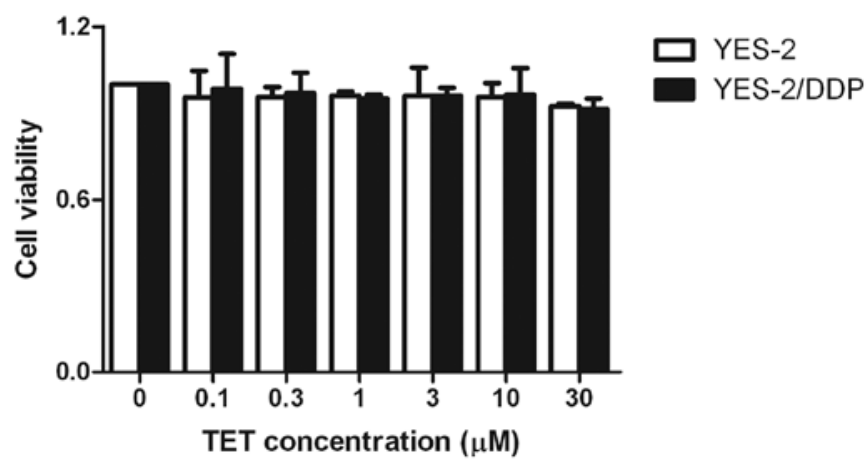

Figure 2. Effect of TET on cell viability of YES-2 or YES-2/DDP cells Cells were treated with an increasing concentration of TET for $72 \mathrm{~h}$; the cell viability was measured by CCK8.

monitor the accumulation of DNA products. Melting curves were performed to assure that the fluorescence was derived from dye intercalating into a specific, homogeneous amplification product. For amplification primers of MDR1, MRP1 and BCRP were 5'-GTG TTT CTG GTC AGC CCA ACT-3' (sense) 5'-TTG GAT CTC AGG ATG GCT AGG-3' (antisense); 5'-GTG TTT CTG GTC AGC CCA ACT-3' (sense) and 5'-TTG GAT CTC AGG ATG GCT AGG-3' (antisense); 5'-ACG AAC GGA TTA ACA GGG TCA-3' (sense) and 5'-CTC CAG ACA CAC CAC GGA T-3' (antisense), respectively. The primers used for amplification of GAPDH cDNA as an internal standard were 5'-CCA CCC ATG GCA AAT TCC-3' (sense) and 5'-TGG GAT TTC CAT TGA TGA CAA-3' (antisense). Each reaction contained $12.5 \mu 1$ of SYBR Premix Ex Taq, $0.5 \mu 1$ of each primer, and $2 \mu \mathrm{l}$ of template made up to $20 \mu \mathrm{l}$ with filter sterilized water. Real-time PCR was performed on a CFX96 Real-time detection systems (Bio-Rad, USA) with initial denaturation at $95^{\circ} \mathrm{C}$ for $30 \mathrm{sec}$ followed by 40 cycles of $95^{\circ} \mathrm{C}$ for $5 \mathrm{sec}, 60^{\circ} \mathrm{C}$ for $30 \mathrm{sec}, 72^{\circ} \mathrm{C}$ for $30 \mathrm{sec}$ and $85^{\circ} \mathrm{C}$ fluorescent signal acquirement. Relative expressions were determined via the $C t$ method normalized to MDR1, MRP1, BCRP or GAPDH standards.

Western blotting. The different treated cells were harvested. Total proteins were prepared according to the method described by the protein extract kit (Piece Biotechnology, Rockford, USA). Protein concentrations were determined by BCA protein assay kit. Protein extracts were fractionated on $12 \%$ polyacrylamidesodium dodecyl sulfate (SDS) gel and then transferred to nitrocellulose membrane. The membrane was blocked with 5\% 


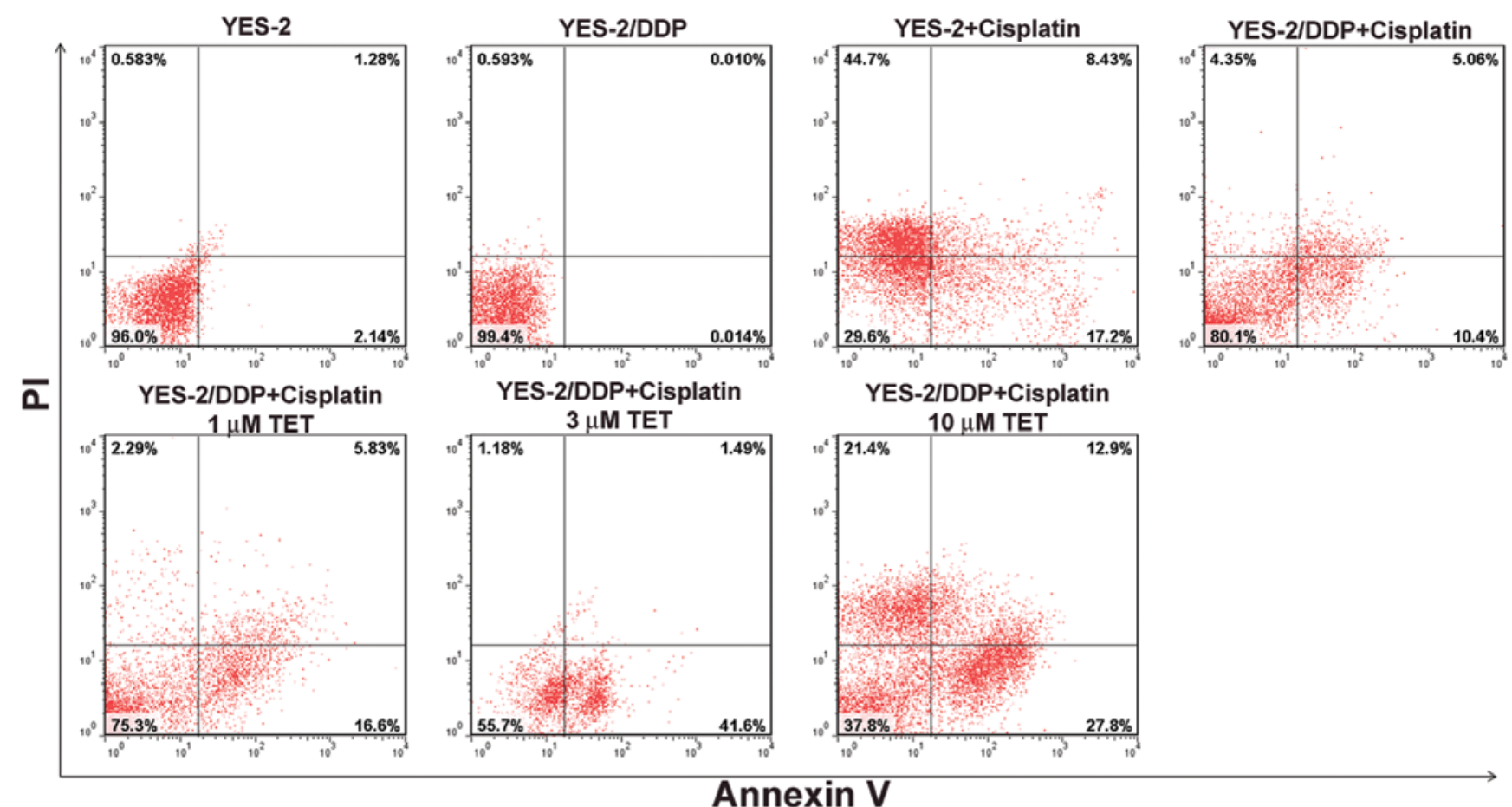

Figure 3. Effect of TET on the cisplatin-induced apoptosis of YES-2/DDP cells. Cells were treated with cisplatin (10 $\mu \mathrm{g} / \mathrm{ml})$ and TET $(1,3,10 \mu \mathrm{M}$, respectively) for $72 \mathrm{~h}$; the apoptosis of cell was measured with a PI and Annexin V kit by flow cytometry.

(w/v) fat-free milk in Tris-buffered saline (TBS) containing $0.05 \%$ Tween-20, followed by incubation with a rabbit primary polyclonal antibody at $4^{\circ} \mathrm{C}$ overnight. Then the membrane was treated with horseradish peroxidase-conjugated goat anti-rabbit secondary antibody $(1: 10,000)$. Antibody binding was visualized with an ECL chemiluminescence system and short exposure of the membrane to X-ray film (Kodak, Japan).

MRPI activity assay. To assess MRP1 activity, a MRP specific probe CMFDA(12) was used to detect intracellular CMFDA accumulation, which is similar to functional activity of drug efflux pumps. Single cell suspensions obtained by trypsinization from confluent monolayers of YES-2/DDP or YES-2 cells, were incubated at $37^{\circ} \mathrm{C}$ for $60 \mathrm{~min}$ in the presence of TET and cisplatin in serum-free DMEM containing CMFDA $1.0 \mu \mathrm{mol} / 1$, then washed three times with ice-cold PBS, resuspended in icecold PBS containing $1 \%$ fetal bovine serum and kept on ice until the analysis by flow cytometry.

Statistical analysis. Results were analyzed using Student's test or by ANOVA where appropriate. All data in this study were expressed as mean \pm SD. P-values $\leq 0.05$ was considered significant.

\section{Results}

The effect of TET on cell viability of YES-2 or YES-2/DDP cells. We first examined the cell viability and cytotoxicity of TET itself on the cisplatin-resistant cell line YES-2/DDP and its parental cell line YES-2. Both cell lines were pretreated with increasing concentration of TET from 0.1 to $30 \mu \mathrm{M}$ for $72 \mathrm{~h}$, respectively. There were no obvious cytotoxicity
Table I. Effect of TET on the $\mathrm{IC}_{50}$ and RI of cisplatin in YES-2/ DDP cells.

\begin{tabular}{lcr}
\hline Cell treatment & $\mathrm{IC}_{50}(\mu \mathrm{g} / \mathrm{ml})$ & \multicolumn{1}{c}{$\mathrm{RI}$} \\
\hline YES-2 & 0.97 & 1.0 \\
YES-2/DDP & 15.91 & 16.4 \\
YES-2/DDP + $1 \mu \mathrm{g} / \mathrm{ml}$ TET & 11.43 & 11.8 \\
YES-2/DDP + 3 $\mu \mathrm{g} / \mathrm{ml}$ TET & 8.62 & 8.9 \\
YES-2/DDP $+10 \mu \mathrm{g} / \mathrm{ml}$ TET & 4.57 & 47.0 \\
\hline
\end{tabular}

on YES-2/DDP and YES-2 treated by varying dose of TET (Fig. 2). Cell survival was $>95 \%$ in both YES-2 and YES-2/ DDP cells when exposed to $10 \mu \mathrm{M}$ or lower concentrations of TET. Therefore, TET concentrations of 1,3 , and $10 \mu \mathrm{M}$ were used in following experiment.

The reversal effect of TET on resistance to cisplatin in YES-2/ $D D P$ cells. In order to investigate whether TET modulated the sensitivity of cells to cisplatin, YES-2 or YES-2/DDP cells were incubated with various concentrations of TET and a full range of concentrations of cisplatin for $48 \mathrm{~h}$. The $\mathrm{IC}_{50}$ and RI of cisplatin in the different treated cells were evaluated by CCK-8. As demonstrated in Table I, it was clear that the sensitivity to cisplatin in YES-2 cells was significantly more than that in YES-2/DDP cells, and TET could effectively reverse the drug resistance dose-dependently. Similar outcome was also shown in the analysis of apoptosis measured by flow cytometry (Fig. 3), TET dose-dependently enhanced cell apoptosis induced by cisplatin. 


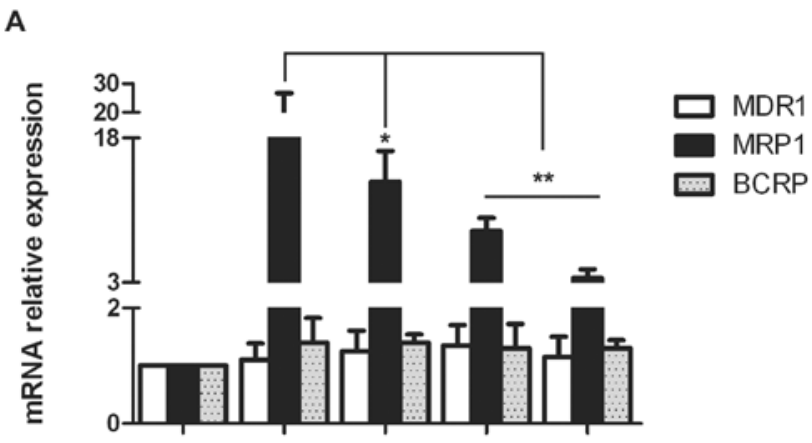

B

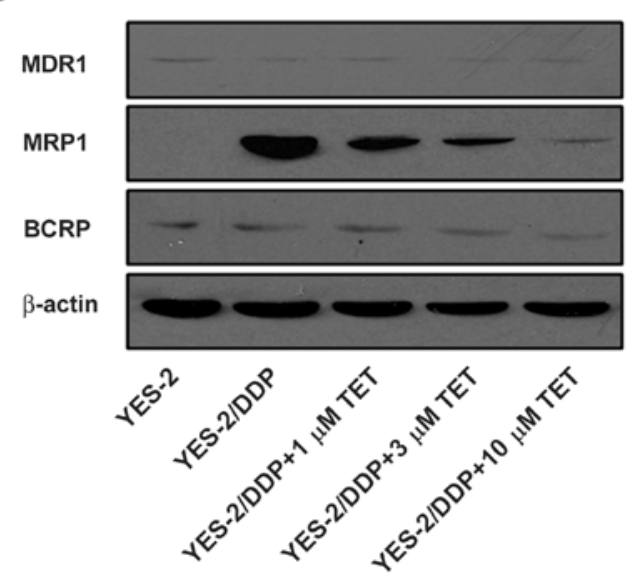

Figure 4. Effect of TET on ABC transporters expression of YES-2/DDP cells. Cells were treated with PBS or different doses of TET $(1,3,10 \mu \mathrm{M}$ respectively) for $72 \mathrm{~h}$; the expression of $\mathrm{ABC}$ transporters were determined by QRT-PCR (A) and western blotting (B). ${ }^{*} \mathrm{P}<0.05,{ }^{* *} \mathrm{P}<0.01$.

The effect of TET on the expression of MDR1, MRPI and $B C R P$. Since the overexpression of ABC transporters in cancers is considered to be a primary determinant of the MDR phenotype, we detected the expressions of three main ABC transporters by qRT-PCR and western blotting to find whether TET reversed the drug resistance to cisplatin through mediating these ABC transporters. It was indicated that MDR1 and BCRP expression have not obvious changes in different treated cells. In contrast, the expression of MRP1 was markedly increased in YES-2/DDP cells, which was dose-dependently decreased by TET (Fig. 4).

The effect of TET on the accumulation of intracellular CMFDA. Based on MRP1 hyperexpression on YES-2/DDP cells, we used a specific MRP1 probe CMFDA to incubate the different treated cells for 60 min. Further, we analyzed the accumulation of intracellular CMFDA in the different treated cells by flow cytometry. As shown in Fig. 5, compared with that in YES-2/ DDP cells, the accumulation of intracellular CMFDA was more intense in drug-sensitive YES-2 cells. It was also demonstrated that TET exhibited dose-dependent enhancement in the accumulation of intracellular CMFDA.

\section{Discussion}

In this study, we first established a human esophageal squamous carcinoma cisplatin-resistant cell subline, YES-2/DDP, which express a high level of MRP1 mRNA and protein, and was 16.4-fold resistant to cisplatin as compared to its parent cell line, YES-2. We found that TET could effectively reverse the resistance of cisplatin in YES-2/DDP cells, and dose-dependently inhibited the expression of MRP1 but not MDR1 and BCRP. Thereby, we deduced that MRP1, $190 \mathrm{kDa}$ glycoprotein mainly localized in cell membrane in almost all tissues, is considered as an ATP-dependent efflux pump and has $14 \%$ structural homology with MDR1, but differs substantially from MDR1. Its main physiological functions involve cellular transportation and secretion, protecting the body from biological damage $(13,14)$. The overexpression of MRP1 has been reported in a variety of human malignancies, which causes increased efflux of chemotherapeutic drugs leading to the occurrence of drug resistance (15-17).

MRP1 can actively transport the drugs into subcellular organelles, or indirectly affect the distribution of drugs to reduce drug concentration in the nucleus, thereby cut down the DNA injury. MRP1 can also reduce the $\mathrm{pH}$ value in the cytoplasm or organelles through forming chloride ion channel or changing channel activity, which will result in the acidic environment where the protonated drugs are largely discharged. In addition, MRP1 can even shift drugs out of cells into the extracellular fluid by vesicle transportation or exocytosis $(14,18,19)$. Numerous studies have shown that inhibition of MRP1 expression by a variety of methods eased the development of drug resistance, thus supported clinical chemotherapy (20-22). Regarding the expression of MRP1 in esophageal cancer, it has been demonstrated that MRP1 often overexpressed in different esophageal cancer cell lines or cancer tissues of patients (23-25). It was even reported that the proportion of MRP1-positive samples in the esophageal cancer was significantly higher than that in the adenocarcinomas of the stomach and the colorectal adenocarcinomas, showing MRP may play a great role in the drug resistance in esophageal cancer (26). Therefore, to find and develop drugs targeting MRP seems to be very favorable for clinical chemotherapy for esophageal cancer.

Many studies have indicated that TET possess a reversal effect on MDR in many cancer cell lines, and might enhance the efficacy of chemotherapy such as cyclosporine A, daunorubicin, etoposide, cytarabine and droloxifene $(27,28)$. It was mostly demonstrated that TET exerted its reversal effect through downregulating MDR1. For example, in human oral cancer MDR KBv200 cells, TET enhanced the antitumor effect of vincristine via directly binding to MDR1 and increasing intracellular VCR accumulation (29). It was even reported that TET exhibited stronger activity to reverse drug resistance to daunorubicin, vinblastine and doxorubicinin in human $\mathrm{T}$ lymphoblastoid leukemia MDR MOLT-4 cells, when compared to well-known MDR1 inhibitor cyclosporine A (CsA) (30).

The derivatives of TET such as $\mathrm{H} 1$, bromotetrandrine and isotetrandrine were also found to be candidates of effective MDR reversing agent in cancer chemotherapy (31-33). In addition to the inhibitory effect of TET on MDR1 expression, it was also shown that TET could significantly inhibit MDR of tumor cells induced by chemotherapy via other means including reducing lung resistance-related protein (LRP) expression, diminishing the activity of topoisomerase II or suppress activation of $\mathrm{NF}-\kappa \mathrm{B}(34,35)$. In this study, we reported that TET had a reversal effect on drug resistance 

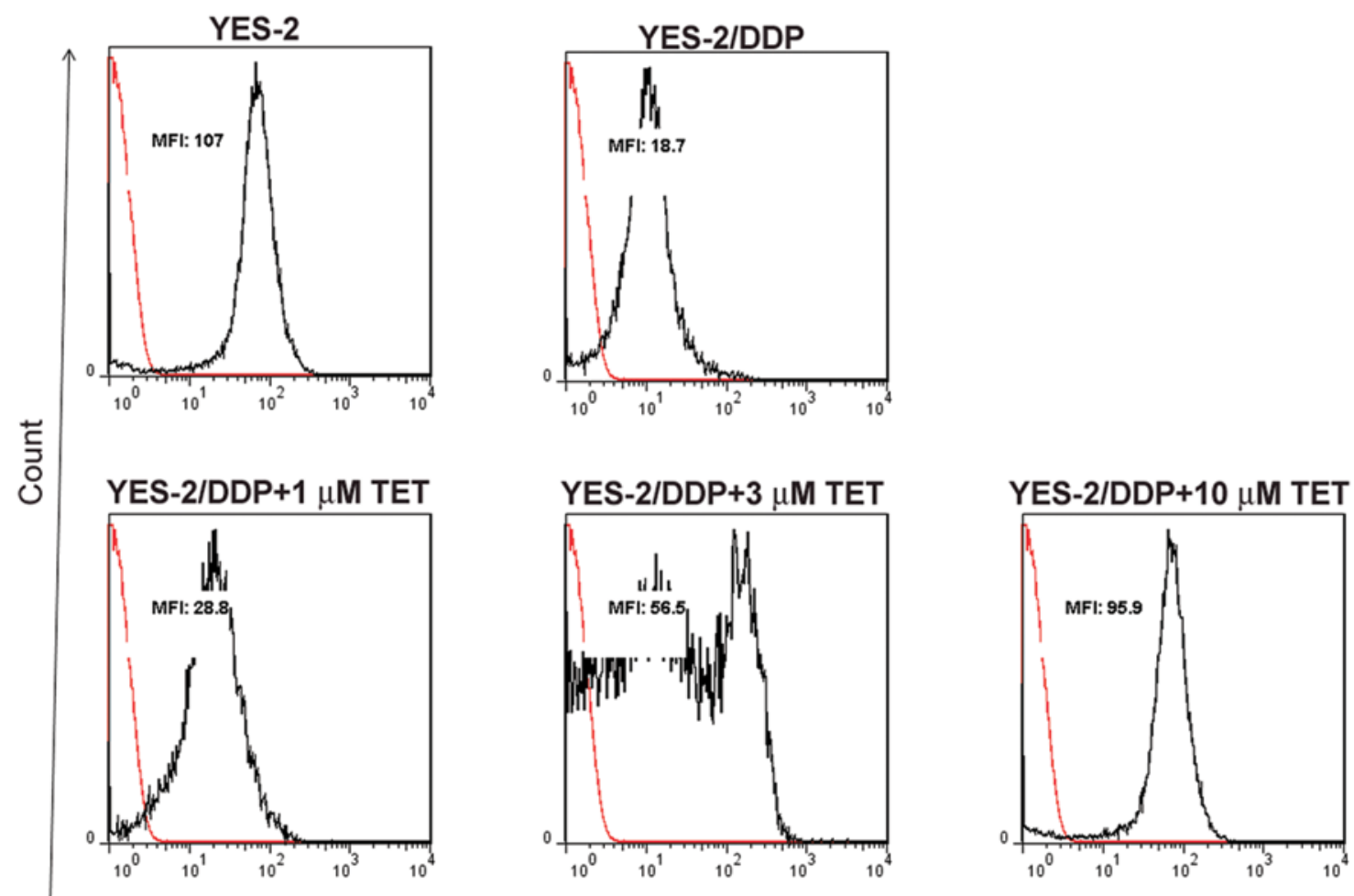

CMFDA

Figure 5. Effect of TET on the accumulation of intracellular CMFDA of YES-2/DDP cells. Cells were treated with PBS or different doses of TET (1,3, $10 \mu \mathrm{M}$, respectively) for $72 \mathrm{~h}$; then cells were loaded with CMFDA for $1 \mathrm{~h}$, cells were washed with PBS three times. Cells were further incubated CMFDA-free medium for $30 \mathrm{~min}$, the mean fluorescence intensity (MFI) of CMFDA were assayed by flow cytometry and indicated as the accumulation of intracellular CMFDA.

to cisplatin in MDR human esophageal cancer YES-2/DDP cells. Compared with untreated YES-2/DDP cells, TET-treated YES-2/DDP cells got more sensitivity to cisplatin. Moreover, further study suggested that TET probably intervened in occurrence of drug resistance by inhibiting MRP1 expression and activity, indicating TET might be considered as a potential adjunct to chemotherapy for esophageal cancer overexpressing MRP1. However, regardless whether TET targets MDR1 or MRP1, the detailed molecular mechanism which TET modulates MDR needs to be further investigated, and has now been thought as the key unsolved question which influences further development of TET as an antitumor drug.

To conclude, we reported that TET reversed drug resistance through regulating MRP1 not MDR1, and has the potential to be an adjunct to chemotherapy for esophageal cancer. Further studies in vitro and in vivo are needed to expound the modulation mechanisms, which will provide a better opportunity to exploit TET.

\section{Acknowledgements}

This study was supported by the National Natural Science Foundation of China (81102007).

\section{References}

1. Wu X, Gu J, Wu TT, et al: Genetic variations in radiation and chemotherapy drug action pathways predict clinical outcomes in esophageal cancer. J Clin Oncol 24: 3789-3798, 2006.

2. Mader RM, Schmidt WM, Steger GG and Krupitza G: Molecular mechanisms of drug resistance. Int J Clin Pharmacol Ther 47 49-50, 2009.
3. Wen J, Zheng B, Hu Y, et al: Establishment and biological analysis of the EC109/CDDP multidrug-resistant esophageal squamous cell carcinoma cell line. Oncol Rep 22: 65-71, 2009.

4. Choi HS, Kim HS, Min KR, et al: Anti-inflammatory effects of fangchinoline and tetrandrine. J Ethnopharmacol 69: 173-179, 2000 .

5. Koh SB, Ban JY, Lee BY and Seong YH: Protective effects of fangchinoline and tetrandrine on hydrogen peroxide-induced oxidative neuronal cell damage in cultured rat cerebellar granule cells. Planta Med 69: 506-512, 2003.

6. Gong X, Luo FL, Zhang L, et al: Tetrandrine attenuates lipopolysaccharide-induced fulminant hepatic failure in D-galactosamine-sensitized mice. Int Immunopharmacol 10: 357-363, 2010.

7. Wu JM, Chen Y, Chen JC, Lin TY and Tseng SH: Tetrandrine induces apoptosis and growth suppression of colon cancer cells in mice. Cancer Lett 287: 187-195, 2010.

8. Li X, Su B, Liu R, Wu D and He D: Tetrandrine induces apoptosis and triggers caspase cascade in human bladder cancer cells. J Surg Res 166: e45-e51, 2011.

9. Zhao QX, Chen BA, Cheng J, et al: Effect of tetrandrine, toremifene and their combination on the reversion of multidrug resistance of K562/A02 cell line. Zhongguo Shi Yan Xue Ye Xue Za Zhi 16: 61-64, 2008 (In Chinese).

10. Zhang H, Gao A, Li F, Zhang G, Ho HI and Liao W: Mechanism of action of tetrandrine, a natural inhibitor of Candida albicans drug efflux pumps. Yakugaku Zasshi 129: 623-630, 2009.

11. Koh HL, Wang H, Zhou S, Chan E and Woo SO: Detection of aristolochic acid I, tetrandrine and fangchinoline in medicinal plants by high performance liquid chromatography and liquid chromatography/mass spectrometry. J Pharm Biomed Anal 40: 653-661, 2006.

12. Roelofsen H, Vos TA, Schippers IJ, et al: Increased levels of the multidrug resistance protein in lateral membranes of proliferating hepatocyte-derived cells. Gastroenterology 112: 511-521, 1997.

13. Bakos E and Homolya L: Portrait of multifaceted transporter, the multidrug resistance-associated protein 1 (MRP1/ABCC1). Pflugers Arch 453: 621-641, 2007. 
14. He SM, Li R, Kanwar JR and Zhou SF: Structural and functional properties of human multidrug resistance protein 1 (MRP1/ ABCC1). Curr Med Chem 18: 439-481, 2011.

15. Abaan OD, Mutlu PK, Baran Y, Atalay C and Gunduz U: Multidrug resistance mediated by MRP1 gene overexpression in breast cancer patients. Cancer Invest 27: 201-205, 2009.

16. Kweon SH, Song JH and Kim TS: Resveratrol-mediated reversal of doxorubicin resistance in acute myeloid leukemia cells via downregulation of MRP1 expression. Biochem Biophys Res Commun 395: 104-110, 2010.

17. EI-Sharnouby JA, Abou EI-Enein AM, EI Ghannam DM, et al: Expression of lung resistance protein and multidrug resistancerelated protein (MRP1) in pediatric acute lymphoblastic leukemia. J Oncol Pharm Pract 16: 179-188, 2010.

18. DeGorter MK, Conseil G, Deeley RG, Campbell RL and Cole SP: Molecular modeling of the human multidrug resistance protein 1 (MRP1/ABCC1). Biochem Biophys Res Commun 365: 29-34, 2008

19. Munoz M, Henderson M, Haber M and Norris M: Role of the MRP1/ABCC1 multidrug transporter protein in cancer. IUBMB Life 59: 752-757, 2007.

20. Payen L, Delugin L, Courtois A, Trinquart Y, Guillouzo A and Fardel O: The sulphonylurea glibenclamide inhibits multidrug resistance protein (MRP1) activity in human lung cancer cells. Br J Pharmacol 132: 778-784, 2001.

21. Wesolowska O, Wisniewski J, Sroda K, et al: 8-Prenylnaringenin is an inhibitor of multidrug resistance-associated transporters, P-glycoprotein and MRP1. Eur J Pharmacol 644: 32-40, 2010.

22. Wang W, Sun YP, Huang XZ, et al: Emodin enhances sensitivity of gallbladder cancer cells to platinum drugs via glutathion depletion and MRP1 downregulation. Biochem Pharmacol 79: 1134-1140, 2010

23. Nooter K, Kok T, Bosman FT, van Wingerden KE and Stoter G: Expression of the multidrug resistance protein (MRP) in squamous cell carcinoma of the oesophagus and response to pre-operative chemotherapy. Eur J Cancer 34: 81-86, 1998.

24. Murase M, Kodera Y, Kondo K, et al: Expression of MRP and mdrl in human gastrointestinal cancer cell lines: a correlation with resistance against doxorubicin. J Surg Oncol 61: 223-229, 1996.

25. Langer R, Ott K, Feith M, et al: High pretherapeutic thymidylate synthetase and MRP-1 protein levels are associated with nonresponse to neoadjuvant chemotherapy in oesophageal adenocarcinoma patients. J Surg Oncol 102: 503-508, 2010.
26. Takebayashi Y, Akiyama S, Natsugoe S, et al: The expression of multidrug resistance protein in human gastrointestinal tract carcinomas. Cancer 82: 661-666, 1998.

27. Chen BA, Guo JJ and Cheng J: Biomolecular mechanisms of cyclosporine A, tetrandrine and their combination on the reversion of multidrug resistance in human leukemia cell line. Zhongguo Zhong Xi Yi Jie He Za Zhi 28: 1010-1013, 2008 (In Chinese).

28. Xu WL, Shen HL, Ao ZF, et al: Combination of tetrandrine as a potential-reversing agent with daunorubicin, etoposide and cytarabine for the treatment of refractory and relapsed acute myelogenous leukemia. Leuk Res 30: 407-413, 2006.

29. Fu L, Liang Y, Deng L, et al: Characterization of tetrandrine, a potent inhibitor of P-glycoprotein-mediated multidrug resistance. Cancer Chemother Pharmacol 53: 349-356, 2004.

30. Liu ZL, Hirano T, Tanaka S, Onda K and Oka K: Persistent reversal of P-glycoprotein-mediated daunorubicin resistance by tetrandrine in multidrug-resistant human T lymphoblastoid leukemia MOLT-4 cells. J Pharm Pharmacol 55: 1531-1537, 2003.

31. Wei N, Sun H, Wang F and Liu G: H1, a novel derivative of tetrandrine reverse P-glycoprotein-mediated multidrug resistance by inhibiting transport function and expression of P-glycoprotein. Cancer Chemother Pharmacol 67: 1017-1025, 2011.

32. Chen LM, Liang YJ, Zhang X, et al: Reversal of P-gp-mediated multidrug resistance by Bromotetrandrine in vivo is associated with enhanced accumulation of chemotherapeutical drug in tumor tissue. Anticancer Res 29: 4597-4604, 2009.

33. Wang TX and Yang XH: Reversal effect of isotetrandrine, an isoquinoline alkaloid extracted from Caulis Mahoniae, on P-glycoprotein-mediated doxorubicin-resistance in human breast cancer (MCF-7/DOX) cells. Yao Xue Xue Bao 43: 461-466, 2008.

34. Li GH, Liu MX, Sun FJ, et al: The effect of tetrandrine on the expression of the P170, LRP and TOPO II in S180's tumor cell induced by chemotherapy in the mice with acquired multi-drug resistance. Zhongguo Zhong Yao Za Zhi 30: 1280-1282, 2005 (In Chinese).

35. Chen BA, Su AL, Cheng J, Zhao HH, Li GH and Wang XM: Effects of tetrandrine on nuclear factor-kappaB expression in leukemia multidrug-resistant cell line K562/A02. Zhong Xi Yi Jie He Xue Bao 6: 956-959, 2008 (In Chinese). 